\title{
BUILDING MANAGEMENT SIMULATION CENTRE
}

\section{B. de Vries, S. Verhagen, A.J. Jessurun}

Department of Architecture, Building and Planning, Eindhoven University of Technology

ABSTRACT: A unique training centre has been built in the Netherlands for construction management. The centre consists of a virtual building site, a (real) site hut for the trainees and a control room. A central role in the course system is played by so-called transitions, which are composed from activities that have to be performed by the trainee. An activity is fulfilled by entering web-based forms with the right content and in the right order. After a training session the system can reproduce all actions that were taken, it can present the consequences for the building and the construction management performance.

KEYWORDS: Training, Virtual Reality, Building and Construction Management, Process Modelling, Simulation

\section{INTRODUCTION TO THE BMSC}

In the Building Management Simulation Centre [www.bmsc.nl] students and experienced construction managers are trained. The main part of the centre is the simulation hall. Here, ten site huts are located with a view on a large parabolic projection screen. The trainee has to execute tasks in the site hut in an environment that is familiar to him/her. Actors play the roles of persons that a construction manager typically faces during his work. A course system is available with all project information and as a medium to communicate with the outer world. On the projection screen the building under construction can be viewed and it can be inspected by navigation through the full-scale model.

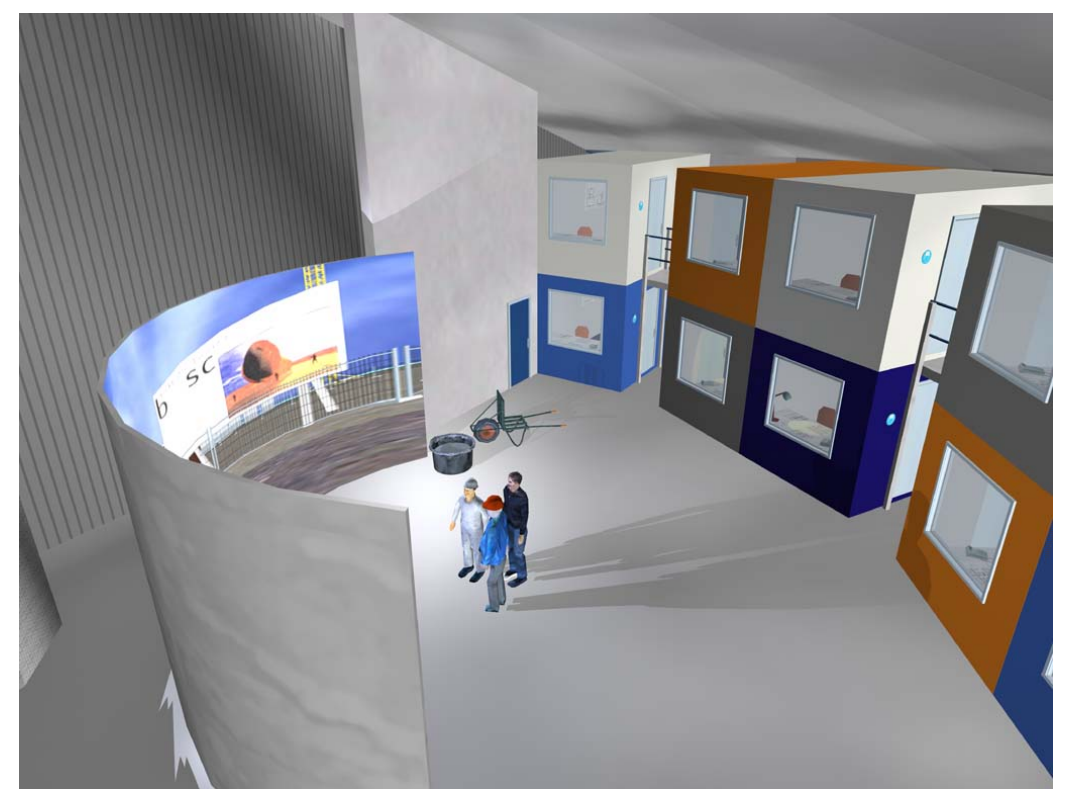

Figure 1: Simulation hall 
The original paper is published as: B. de Vries, S. Verhagen, A.J. Jessurun. Building Management Simulation Centre. In: Proceedings of the CIB-W78 International Conference on IT Construction in Africa, Pretoria, South Africa, 29 May - 1 June, 2001.

Similar VR based training systems can be found in the aircraft industry, the automotive industry [http://www.ttsl.co.uk/home.htm] en de shipbuilding industry [http://thor.sv.vt.edu/crane/]. These examples inspired the initiators of the BMSC to investigate if the same methodology could be used in the building industry

Construction process simulation research has mainly been focused on the development of a construction planning analysis tool (Kamat, Martinez 2000). In the BMSC though, interaction between the construction manager and the building on the building site will steer the construction process simulation.

\section{BACKGROUND}

In the Netherlands a report (RRBouw 1997) was published that concluded that the traditional construction manager was primarily responsible for the building technology aspects whereas the new generation construction manager is also planning the construction process. The function description of the new construction manager is summarized as follows:

- Planning and project preparation

Project analysis, process analysis, contract plan

- Construction preparation

Main construction plan, cost calculation, quality assurance plan, organisational plan, information plan

- Construction

Preparation of the work tasks, management of the work tasks, evaluation of the construction progress

Another conclusion that was drawn in the report, was that current training programs do not match with this new kind of construction manager. From this, the initiative was taken to develop a new training program. The committee that was appointed created a shortlist of targets that were to be reached by the new training programs, namely:

1. Reduction of failure costs

2. Construction quality improvement

3. More pre-active instead of re-active construction management

To date construction managers are trained on the building site. Disadvantages of this way of training are obvious: very much dependent on the kind of building project and on the trainer. It was decided that the training should be performed in a more controlled way to assure that every student has faced similar situations and problems. The only way to reach this goal is to create a building site that can be fully controlled in order to perform specific exercises. To obtain maximum flexibility and controllability it was decided that this would be a virtual building site.

Apart from creating the virtual building site, a major task was to design the course system. Before actually designing the course system a formal description was needed of the construction manager's activities and more precisely how these activities are scheduled and rescheduled. 
The original paper is published as: B. de Vries, S. Verhagen, A.J. Jessurun. Building Management Simulation Centre. In: Proceedings of the CIB-W78 International Conference on IT Construction in Africa, Pretoria, South Africa, 29 May - 1 June, 2001.

\section{TRANSITIONS}

Discussions with construction managers and observations on the building site taught us that construction managers organize their work in a limited set of work patterns called transition types. The transition types that were identified are:

- Checking completeness of information

- Registration of the status before construction

- Description of the work task

- Delivery of material and management of subcontractors

- Communication of the work tasks with the workers

- Registration of the status after construction

- Logging of data

Transition types are decomposed into activity types. Transition types and activity types are the generic, project independent descriptions. For a specific project the appropriate transition types need to be selected and each of them need to be accommodated with the appropriate activities. Accommodation is achieved by inserting the project dependent values into the activity description.

Transitions play a central role in the system. For the training system two typical building project were selected: an office building and a plan with 14 houses. Since the selected projects were recently finished there was an opportunity to deduce all activities from interviews with the involved construction managers. In total about 100 activities were identified.

The exercise should be a reflection of an 'ordinary' day of a construction manager. An exercise involves at least one transition type. A trainee will execute a combination of exercises during one session, which will cover a range of aspects of construction management.

While performing the activities, a log record will be kept per session for each student. After completing an activity a score rule is fired which results in a response from the system to the trainee and in entering a record into the session log.

Following the above-explained line of thought, a global data schema can be constructed.

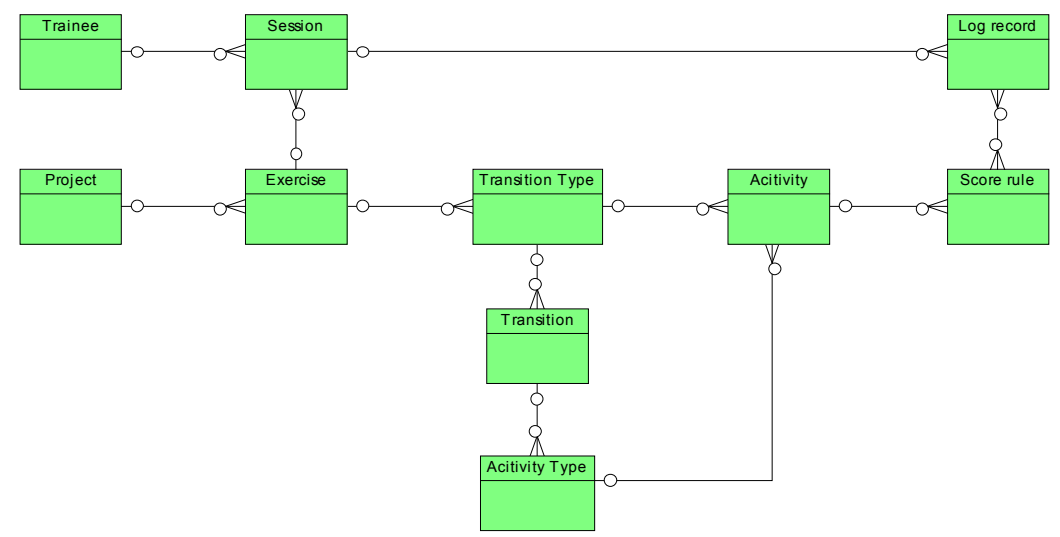

Figure 2: BMSC course system schema 
The original paper is published as: B. de Vries, S. Verhagen, A.J. Jessurun. Building Management Simulation Centre. In: Proceedings of the CIB-W78 International Conference on IT Construction in Africa, Pretoria, South Africa, 29 May - 1 June, 2001.

\section{SYSTEM REQUIREMENTS}

The course trainers expressed that they wanted as much data to be logged about the students' actions and behaviour as possible. These data would allow for objective analysis afterwards and conclusions on how to improve. General guidelines for system design and development were:

- Minimal data entry effort

- Maximal data reliability

- Maximal data accuracy

- Minimal trainer's interference

The construction manager uses several communication media, such as: documents (reports, drawings), telephone, fax and of course face-to-face verbal conversation. In the training situation these circumstances should be similar as possible. In practice, registering the construction process, updating the construction planning, managing the building material delivery, etc. is all done by creating and updating documents whether or not supported by computer systems. The training system should be able to trace the document management actions of the trainee and it should be able to interpret the data input.

After a training session it must be possible to check the consequences of the trainees' decisions. These are consequences for the final building but also for general criteria such as cost.

\section{BMSC COURSE SYSTEM}

The BMSC course system consists of three main elements, namely the building site, the site hut of the construction manager (i.e. the trainee) and the control room.

The building site is presented by means of a Virtual Reality model. The image is projected on a parabolic screen of approx 10 by 5 meter. The model contains very much detail, which is necessary because it should allow the construction manager to check the construction. Every single part of the construction is there. The VR model is used before the training session, during the training session and after the training session. Before the training session the building site and the current status of the building will be presented to the trainee. During the training session the trainee can navigate him/herself through the VR model and check status and conditions. After the training session the trainee will be confronted with the final building. Evidently the final building is dependent on the trainee's actions and decisions. The consequences will be visualized in the VR model.

The site hut is a replica of a 'real' construction manager's site hut. Hence, there are a layout table, a telephone, a planning schema and a computer. Moreover there are actors that play the role of, for instance: a truck driver that wants to deliver his materials, a salesman that wants to introduce new products, the new owner of the building, etc. These people interfere with the day-to-day work tasks and demand immediate action of the trainee. The role parts that are played are conducted by the trainer. The computer is the only instrument to consult data, send out requests, to place new orders, etc. For data-retrieval an extensive library of documents is available concerning the project. For data-entry, forms are available with common objects like radio buttons, lists, check box, etc, and text fields. There are data-entry forms for every foreseen action that can be taken by the trainee. After completion the data are submitted to the system and interpreted by the system. Once submitted, documents can be retrieved and 
The original paper is published as: B. de Vries, S. Verhagen, A.J. Jessurun. Building Management Simulation Centre. In: Proceedings of the CIB-W78 International Conference on IT Construction in Africa, Pretoria, South Africa, 29 May - 1 June, 2001.

edited if necessary. After system interpretation the trainee might get a response in the form of a new document.

In the control room the trainer can trace the trainee's actions by means of the course system. Moreover, video cameras and microphones are installed in the site huts. This is especially useful to watch the trainees responses to the role players.

\section{Student Interface}

The system entry point for the trainee is the project menu. The menu items are well known attributes for the construction manager. The menu structure is not hierarchical, hence there is more then one way to find specific information. The project menu structure is as follows:

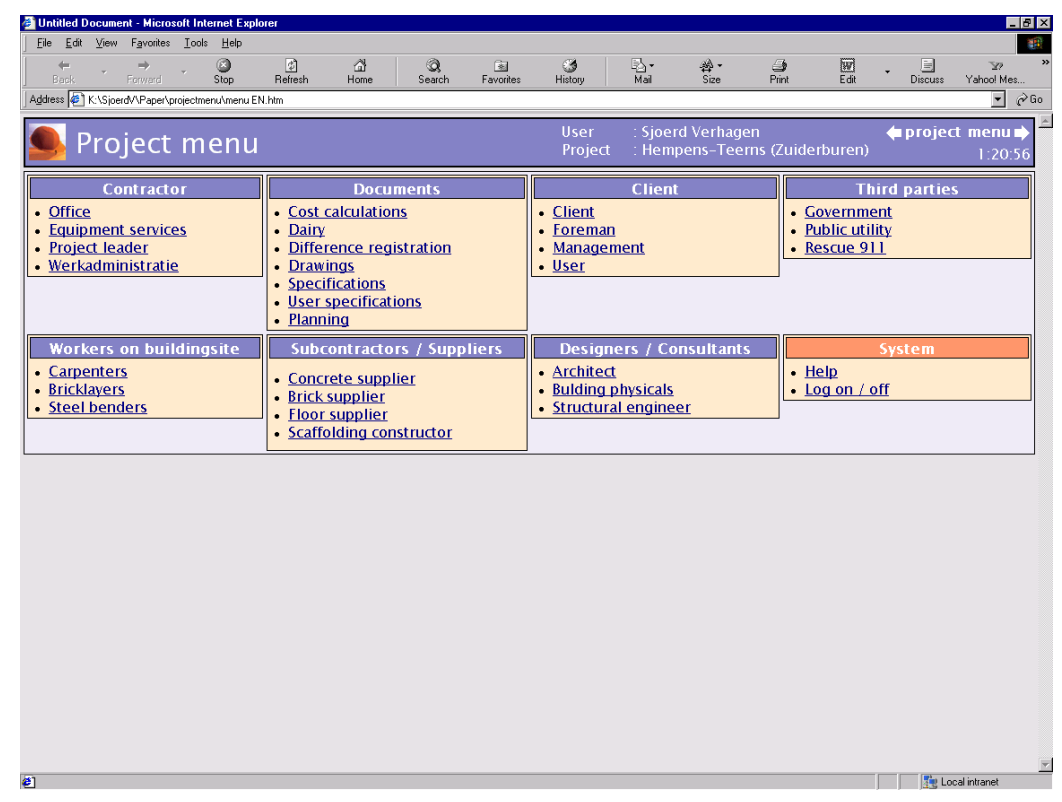

Figure 3: Project menu

The Contractor section contains communication tools and information about the organisation. The documents section contains all relevant documents of the project. It also contains documents to take action. Checklists are offered as an instrument for performing checks on completed building parts or other components. In the dairy all problems and their solution are registered. The Workers on building site section is the part where you can contact the other workers who are working on the site.

In the Subcontractor, Designers and Client section, all the information (messages, documents, drawings, etc.) is stored about a participant.

The Third parties section contains some additional information that might be necessary for acquiring data and for unforeseen circumstances.

Finally, each trainee is uniquely identified by his/her account.

\section{Teacher Interface}

Before the training session, the trainer selects the exercise for the training session. All trainees are introduced into the situation using documents that are copied from the original real building project and using the VR model. During the training session the trainer can monitor all actions (e.g. retrieval of a document) that are taken by the trainee. The action list (i.e. the $\log$ record) is presented for each student including a time stamp and it gives direct access to the action's content. The teacher manages the role players using a scenario and watches the trainees responses on the television monitor. If necessary the trainer can act 
The original paper is published as: B. de Vries, S. Verhagen, A.J. Jessurun. Building Management Simulation Centre. In: Proceedings of the CIB-W78 International Conference on IT Construction in Africa, Pretoria, South Africa, 29 May - 1 June, 2001.

differently from the scenario. After the session the trainer can evaluate the training together with the trainee. The evaluation results are accumulated to five aspects, namely Time, Cost, Quality, Organization and Information [Wijnen, Renes, Storm 1988]. For each activity there is a rule that specifies the positive or negative consequences for one or more of these aspects. The scores are within a range from 1 to 5 . Another evaluation result is the final building that can be viewed as a VR model. Dependent on the decisions that were made, the model will show which building components or building parts could effectively have been constructed.

\section{SYSTEM SETUP}

In the central hall of the building of the Building Management Simulation Centre, the parabolic screen and the construction manager site huts are located. For cost efficiency reasons there are 10 site huts, thus 10 trainees can follow the course concurrently. Because of this their might occur a problem if two students at a certain moment want to check the building site. In practise though, this turns it to be a minor problem that only incidentally occurs. Next to the central hall there are rooms for the introduction and for the evaluation.

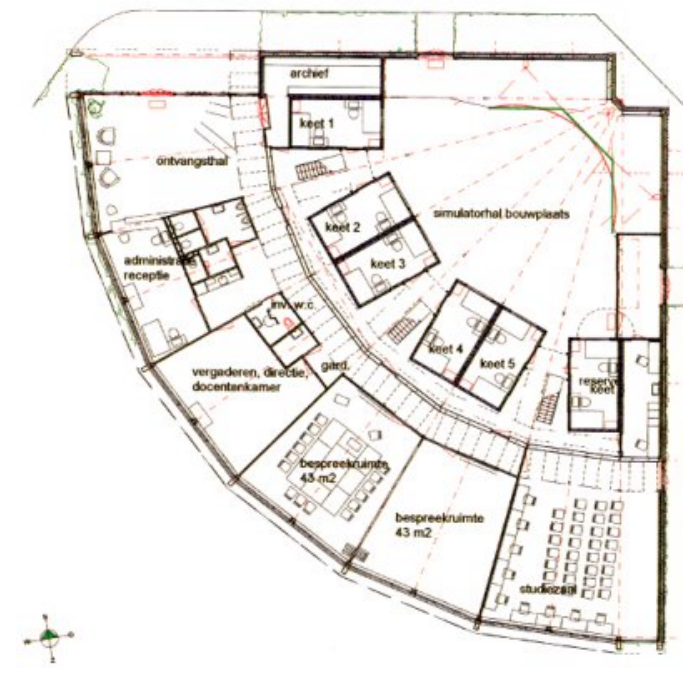

Figure 4: Floor plan of the BMSC

Forms play a central role in the communication between the trainee and the system. The trainee communicates with the simulation using HTML forms displayed as web pages. Many forms in the course system have the same layout and content and only differ in components like other default values for fields or another entry in a combo box. This is one of the reasons why the form template with merge data method has been implemented. Another advantage is that the system can be constructed from standard form templates that can be used as building blocks. To implement this we used XML [W3C-XML 1998].

XHTML is a reformulation of HTML in XML, and combines the strength of HTML with the power of XML. A form template is an XML file containing a normal XHTML page including a form. By naming the different fields in this template it is possible to replace values using merge data. Merge data is XML content describing what to change in the form template to get the final XHTML form the user should see. During the merging some additional changes are made to the result, so that the form is a correct XHTML page that functions as the system expects. 
The original paper is published as: B. de Vries, S. Verhagen, A.J. Jessurun. Building Management Simulation Centre. In: Proceedings of the CIB-W78 International Conference on IT Construction in Africa, Pretoria, South Africa, 29 May - 1 June, 2001.

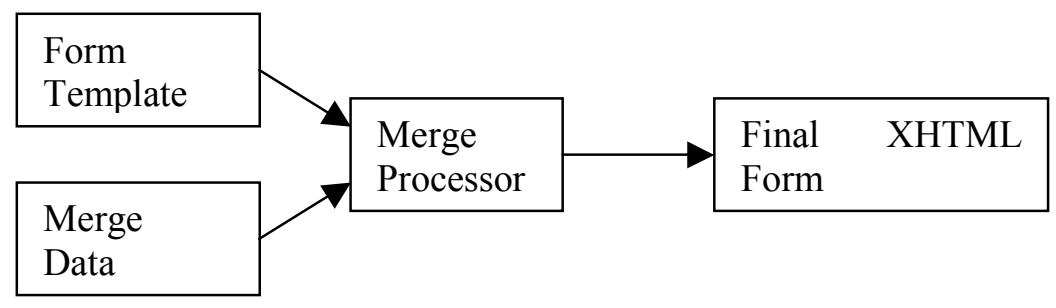

Figure 5: Form Template with Merge Data

Below is a small sample form template. It describes a combo box with Sunday as default value.

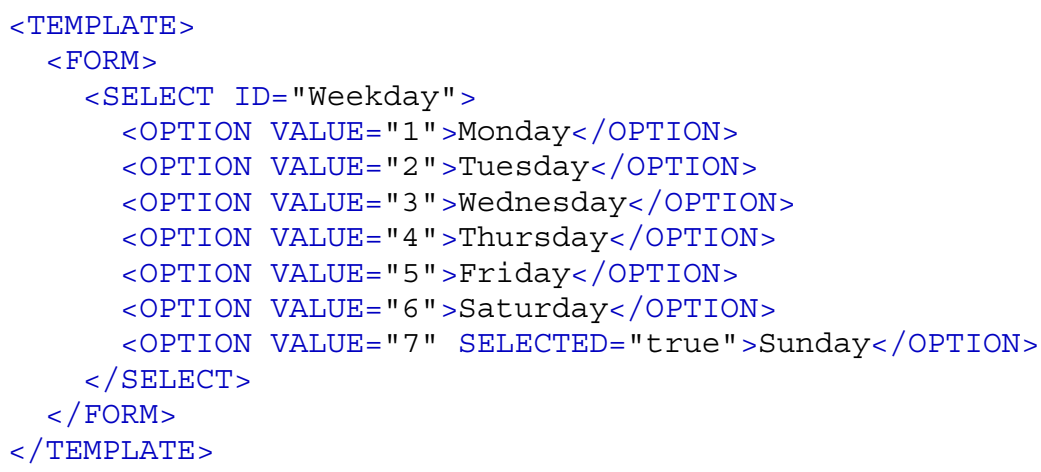

By using the following merge data with the form template above you can change the defaultselected value of this combo box. The merge data expresses that the default selected option of the select element with id value "Weekday" should be the option with value 1, being "Monday".

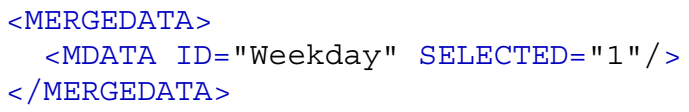

This is only one simple example of what you can do with the merge data.

Forms are defined at the project level, the exercise level and on the transition type level. Subsequently selecting the project and the exercise will start the generation of the course environment consisting of web pages with static information and web pages that are dataentry forms for triggering activities.

Data entries are evaluated by matching the trainees' data with the data that are stored in the system by the trainer using the score rules. When a trainee submits a form to the system, all data in the form is saved in a session log file. A log entry is a set of tupels containing name, value pairs:

FormCode $=\mathrm{P} 1.1$

Weekday $=4$

In the example above a trainee has submitted a form with the code P1.1. This code is a code for a merged XHTML form. In this form he selected "Thursday". The log entry will also contain some more information like at what time the form has been posted. 
The original paper is published as: B. de Vries, S. Verhagen, A.J. Jessurun. Building Management Simulation Centre. In: Proceedings of the CIB-W78 International Conference on IT Construction in Africa, Pretoria, South Africa, 29 May - 1 June, 2001.

The scoring system works on the bases of so called score items. For every activity in an exercise, a list of score items is defined. To determine if a score item fires, the following data is available:

- To what form the score item belongs.

- An expression that will be matched against the log entry. An example of an expression is: Weekday $>1$ And Weekday $<=4$

- The priority of the score item. A score item with a higher priority will take precedence over one with a lower priority.

For every log entry all score items are matched. This is done by sorting the score items on priority and then evaluating the expression in the score item using the variables from the log entry. Only score items of the same form are being evaluated. The first score item that evaluates the expression, as being true, will be fired. When a score item fires the activity it belongs to is marked as handled. A fired score item contains information for the evaluation of the trainee:

- The new state of the virtual reality environment.

- Other activities that are considered as being handled.

- The score for finished the activities.

- Scores for reducing or increasing the values of the cost, time, etc. criteria.

The BMSC course system is implemented using MS SQL Server and Internet Information Server. The toolkit for creating and updating templates and forms is developed in Delphi 5.

\section{TRAINING EVALUATION}

The trainee's performance can be judged according to the transition types, the five evaluation aspects, construction knowledge and management knowledge.

The emphasis of the course is on the correct execution of the transitions. To do so, the trainee must first recognize the right transition type for the problem he is confronted with. After that he can start performing the activities that are required for this transition type. After the training session the transitions will be presented and the activities that were executed. For each transition type the system will indicate if the appropriate activities were executed. For each activity the system will indicate if it was executed correctly or not. The activity's content (i.e. a document) can be inspected for clarification.

The overall performance of the final construction will be quantified to Time, Cost, Quality, Organization and Information. These quantifiers help the student in understanding the often conflicting implications of his decisions.

Last but not least the trainer will have an overall impression of the student regarding his construction (management) performance. Trainers are recruited from practice and therefore well qualified for this job.

\section{FIRST EXPERIENCES}

Because of the novelty of the training method, the BMSC received al lot of attention. Most visitors and trainees expressed that that did not have any clue what the training would be like. Afterwards they said that the level of realism of the training was overwhelming and that the courses are very intense. Communication by means of the course system was sometimes experienced unnatural. In real life the phone plays a very important role. The problem with this medium is that it allows for informal agreements that are very hard to control. 
The original paper is published as: B. de Vries, S. Verhagen, A.J. Jessurun. Building Management Simulation Centre. In: Proceedings of the CIB-W78 International Conference on IT Construction in Africa, Pretoria, South Africa, 29 May - 1 June, 2001.

The toolkit has proven its flexibility in creating any kind of documents that was needed. The price for flexibility is the quite laborious task of extending and updating a course. Even though the two projects that are available now are worked out in very much detail, it appeared that there are still some unforeseen actions missing in the system. The creativity of the trainee in solving problems often goes beyond what the trainer can think of.

\section{ACKOWLEDGEMENTS}

Michiel Schrijver, the director of the BMSC, offered us a great service in sharing his experiences with the courses and with the course system especially. Walther Roelen, the director of Calibre b.v. provided us the rendering and he was the chief executive officer of the project.

\section{REFERENCES}

RRBouw (1997). De bouwplaatsmanager geportretteerd: Het profiel van de manager op de bouwplaats, Research rapport 92, Zoetermeer, The Netherlands (in Dutch).

Kamat, V.R. and J.C. Martinez (2000). 3D Visualization of Construction Processes and Products, In G. Gudnason (ed.) Construction Information Technology 2000, Proceedings of CIT2000. Reykjavik, Iceland, 506-512.

W3C-XML (1998). Extensible Markup Language (XML) 1.0, World Wide Web Consortium Recommendation, http://www.w3.org/TR/REC-xml//

Wijnen, G., W. Renes and P. Storm (1988). Project matig werken, Het Spectrum b.v., Zeist, The Netherlands (in Dutch). 